\title{
TREATMENT FOR CANINE CORNEAL ULCER USING ADIPOSE TISSUEDERIVED MESENCHYMAL STEM CELL THERAPY - CASE REPORT
}

\author{
Arantes-Tsuzuki, P. M.; Mazzonetto, P. C.; Lo Turco, E. G. \\ petra.arantestsuzuki@gmail.com; patricia.mazzonetto@gmail.com; edsonlt@gmail.com \\ Affiliation: Medmep Excelência em Medicina Personalizada \\ Indiana Street, 922, Brooklin Paulista, São Paulo, Brazil
}

Abstract

Corneal ulcer (CU) is an ophthalmopathy characterized by depression of the corneal surface with at least one stromal loss. $\mathrm{CU}$ is common in canine and feline species and is usually caused, among others, by trauma, infections, toxic contamination and endocrine disorders. They usually result from an increased inflammatory response and are associated with some clinical signs such as blepharospasm, photophobia, epiphora, pain and loss of corneal transparency. Despite advances in conventional and pharmacological therapy, in many cases indolent and recurrent ulcer treatments still lead to loss of visual acuity of the animal. This paper aims to report the effect of topical application of canine adipose tissuederived mesenchymal stem cell (cATMSCs) as treatment of recurrent CU in a Poodle dog breed that showed clear difficulty in the healing process associated with diabetes. The animal was submitted to two applications of cATMSCs and showed improvement in the blepharospasm, conjunctival hyperemia, mucopurulent ocular secretion, photophobia, corneal opacity, chemosis, pigmentation, neovascularization, and pain parameters. Besides, Fluorescein test, Schirmer test and ocular fundus exam also showed improvement in their values concomitantly with lesion resolution. Due this, we showed that cATMSC therapy contribute to the regeneration of corneal tissue in CU and may contribute to the treatment to others ophthalmopathies.

Key-word: Eye. Corneal ulcer. Canine. Mesenchymal stem cell. Cell Therapy. 


\section{Introduction}

The cornea is the refractive component of the eyeball, responsible for transmitting light to the retina and for acting in the image focusing process. The cornea is formed by 5 layers including epithelium layer that reside limbal stem cells. This population is important to maintaining the integrity of the corneal surface and transparency of the córnea (Banks, 1992; Gelatt, 2003; Sridhar, 2018; Le, 2018).

Due to constant exposure to the environment, the cornea becomes more susceptible to traumatic, chemical and biological lesions, which can culminate in ulcerations, i.e. corneal surface depression with at least a stromal loss (Gelatt, 2003).

Corneal ulcer (CU), among eye diseases, is one of the most common ophthalmopathies in dogs and cats, and is commonly caused by trauma (Gilger et al 2007). Other causes also include infections, toxic contamination, and endocrine disorders such as diabetes mellitus (Beam, et al., 1999; Koehler, et al., 2003).

The diagnosis of $\mathrm{CU}$ is made by clinical signs that present characteristics such as blepharospasm, photophobia, epiphora, pain and loss of corneal transparency and, by specific tests, such as fluorescein staining (Slatter, 1990).

CU can be superficial to deep. In mild cases, they are superficial and usually self-limiting, and treatment is usually performed through antimicrobial eye drops to avoid infectious associations, which may cause loss of corneal transparency, with consequent decrease in acuity even after healing. In more severe cases, CUs may be refractory and/or progress to ocular perforation, with lesions that may be irreversible, causing vision loss (Gelatt, 1991). In these cases, treatments conventionally may include from antimicrobial eye drops, antibiotics, non-steroidal and steroidal anti-inflammatory treatments, and even surgery (Kern, 2003; Slatter, 2007).

Due to the scarcity of treatments with high adherence rate, unresponsive treatments in refractory cases and severe cases requiring invasive interventions, such as blepharorrhaphy surgery or even corneal transplantation (Gonçalves, 2000; Gellat, 2003 ; Slatter, 2005), the application of mesenchymal stem cell (MSC) therapy is considered a promising alternative since they act directly on tissue restoration through regeneration, transdifferentiation, anti-inflammatory and immunomodulatory mechanisms (Lan et al, 2012). MSC are multipotent cells that are capable of differentiating in cells of three embryonic layers. Besides, MSC are found in many tissues including cord blood, bone 
marrow, limbal stroma of eye and adipose (Pittenger, 1999; Yao, 2013; Öner, 2018). Some growth factors, cytokines and other biomolecules present at the site of injury are signals for the natural tropism of stem cells by niches of inflammation. Thus, MSC, after application, are attracted to the damaged site where they are stimulated and start acting by the mechanisms already mentioned (Deans and Moseley, 2000; Bobis et al., 2006; Ma, Chan, 2016).

Thus, this case report aims to register and corroborate the studies that highlight the beneficial action of canine adipose tissue-derived mesenchymal stem cells (cATMSC) in the treatment of $\mathrm{CU}$ in dogs.

Materials and methods

A castrated female Poodle dog, 14 years old and $5.4 \mathrm{~kg}$ diagnosed with recurrent CU in the left eye on August 20, 2017 due to a corneal injury by a specialized ophthalmology service, in the city of São Paulo was treated using cATMSC therapy.

The patient was diabetic and was in an unstable state, without ketoacidosis, but showing clear difficulty in the healing process. She also had other comorbidities such as hyperadrenocorticism, mitral valve insufficiency, and grade I diastolic dysfunction. She was treated daily for these comorbidities with trilostane with benzafibrate $(5 \mathrm{mg})$, silymarin (liver protector), clopidogrel, and insulin.

The patient presented clinical manifestations due the CU such as blepharospasm, conjunctival hyperemia, mucopurulent ocular discharge, photophobia, corneal opacity, chemosis, neovascularization and ocular discomfort.

Diagnostic confirmation of the ulcer was performed by fluoresceinpositive staining (Figure 1). Schirmer test (ST), ocular fundus exam (OF) and biomicroscopy were also performed for follow-up and differential diagnosis. Specifically, the patient was medicated for 15 days with eye drops EDTA $0.35 \%$, Zymar ${ }^{\mathrm{TM}}$, Acular ${ }^{\circledR}$ LS and ointment for ophthalmic treatment.

After the conventional treatment without significant evolutions, the patient underwent therapeutic intervention with two allogeneic stem cells topical eye application. The ATMSC were collected from non-defined breed (NDB) donor dog, female, 1,8 years old. The isolated tissue was washed with phosphate buffered saline (PBS) and dissociated by enzymatic degradation using collagenase. After that, MSC was plated in bottles and 
incubated at $37^{\circ} \mathrm{C}$ using supplemented medium. The medium was renewing each 48 hours until reaching the stipulated cell concentration for the application.

The first application was performed by administering $3 \times 10^{6}$ cATMSC in a volume of $400 \mu 1$, passage 2 . The second application was performed 48 days later and was administered by $3 \times 10^{6}$ cATMSC in volume of $400 \mu \mathrm{L}$, passage 3 . The patient was clinically evaluated: 4 days before the first application, on the day of application, 7, 21, 48, and 69 days after the first application of the cells. The parameters used for the evaluation were: intensity or presence/absence of blepharospasm, conjunctival hyperemia, mucopurulent ocular discharge, photophobia, corneal opacity, chemosis, pigmentation, neovascularization and pain. Complementary examinations such as the ST and $\mathrm{OF}$ were also performed during these periods.

Results

The female Poodle dog with recurrent CU in the left eye was diagnosed with a positive fluorescein label (Figure 1). ST, OF and biomicroscopy were also performed for followup and differential diagnosis.

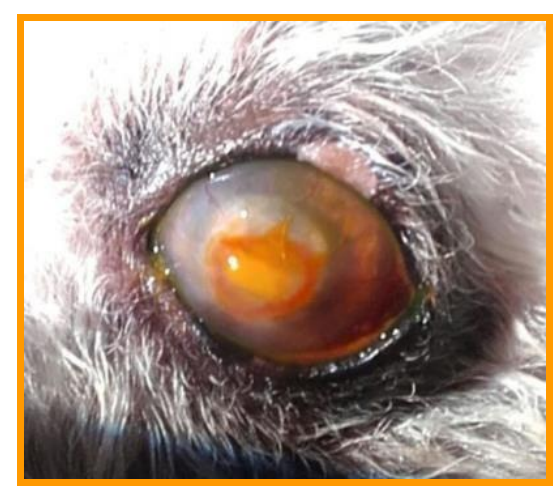

Figure 1. Fluorescein test stain showed corneal injury. Photograph of the left eye of a female Poodle dog with CU under fluorescein test with positive result.

The clinical evaluation was performed 4 days before the first application, on the day of application, 7, 21, 48, and 69 days after, showed improvement in most parameters of blepharospasm, conjunctival hyperemia, mucopurulent ocular discharge, photophobia, corneal opacity, chemosis, pigmentation, neovascularization and pain (Table 1). 
Table 1. cATMSC therapy showed improvement in clinical signs in corneal ulcer diagnosis. Evolution of clinical signs and results of complementary tests after topical application of cATMSC. +++: very severe symptom; ++: severe symptom; +- or +: moderate symptom; -: no symptoms. F: ocular fundus exam; ST: Schirmer test.

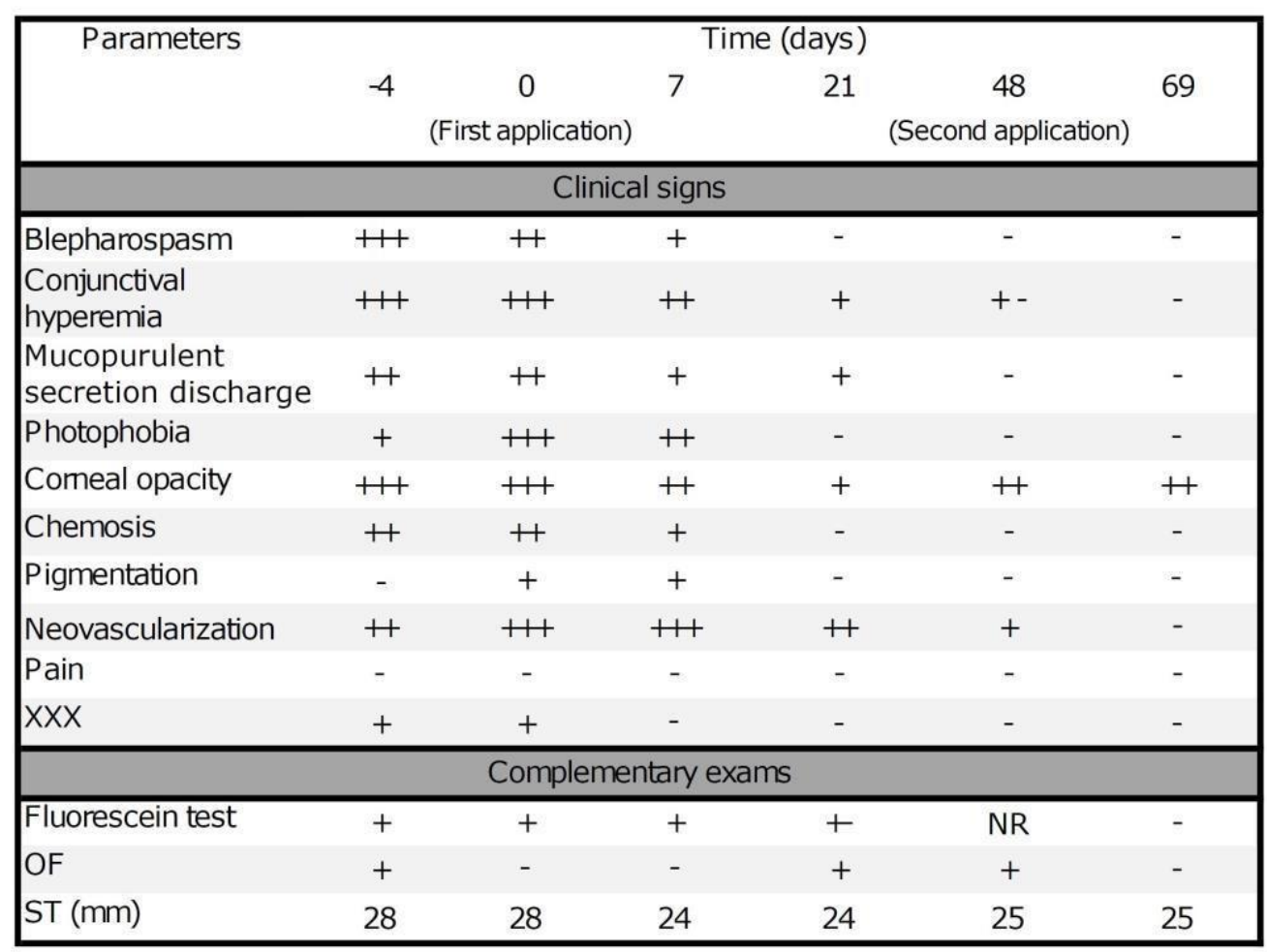

After the second application, all evaluated parameters showed significantimprovement, as indicated in Table 1 and shown in Figure 2. 


\section{Evolution of clinical signs}

\begin{tabular}{|c|c|c|c|}
\hline \multicolumn{4}{|c|}{ Blepharospasm } \\
\hline O & • & • & • \\
\hline
\end{tabular}

\begin{tabular}{|c|}
\hline \multicolumn{2}{|c|}{ Photophobia } \\
\hline \\
\hline
\end{tabular}
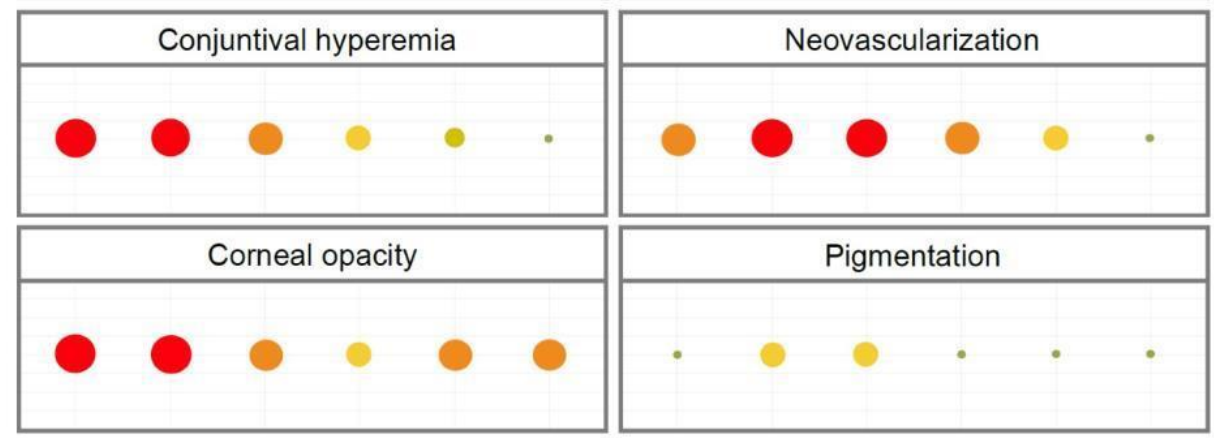

Signs

- 0
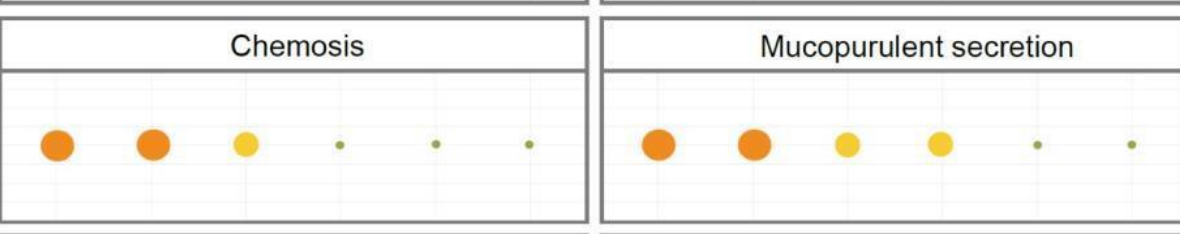

1

2
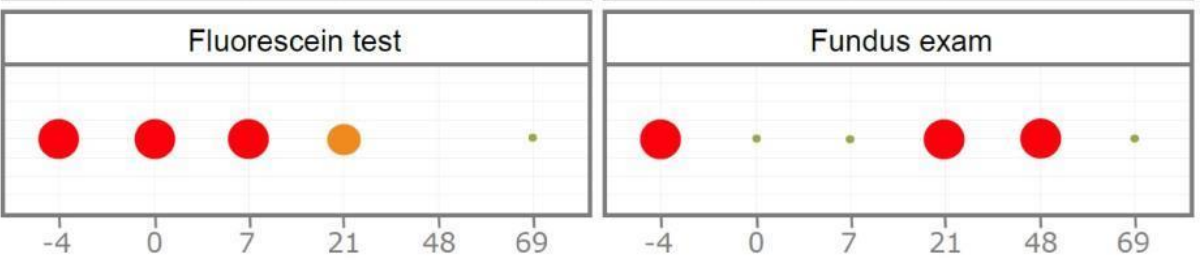

Application days

Figure 2. Female Poodle showed improvement of clinical signs after cATMSC therapy. Illustration of the evolution of clinical signs and results of complementary fluorescein test and fundus exam after cATMSC therapy. 3. Red ball: very severe symptom; 2. Orange ball: severe symptom; 1. Yellow ball: moderate symptom; 0. Green ball: no symptoms. Created by software R project for statistical computing.

The fluorescein test was repeated after cATMSC therapy and showed negative result (Figure 3). Besides, ST and OF also showed improvement in their values concomitant with lesion resolution, and their results were observed in Table 1, Figure 2 and 4. 


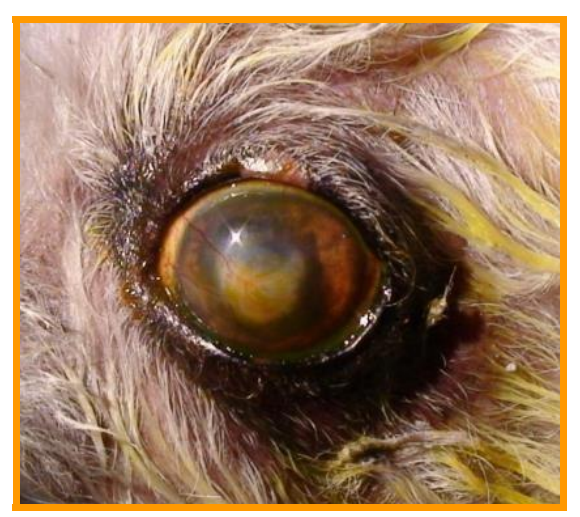

Figura 3. Fluorescein test stain showed absence no corneal injury after cATMSC therapy. Photograph of the left eye of a female Poodle dog after cATMSCs therapy submitted to fluorescein test with negative result.

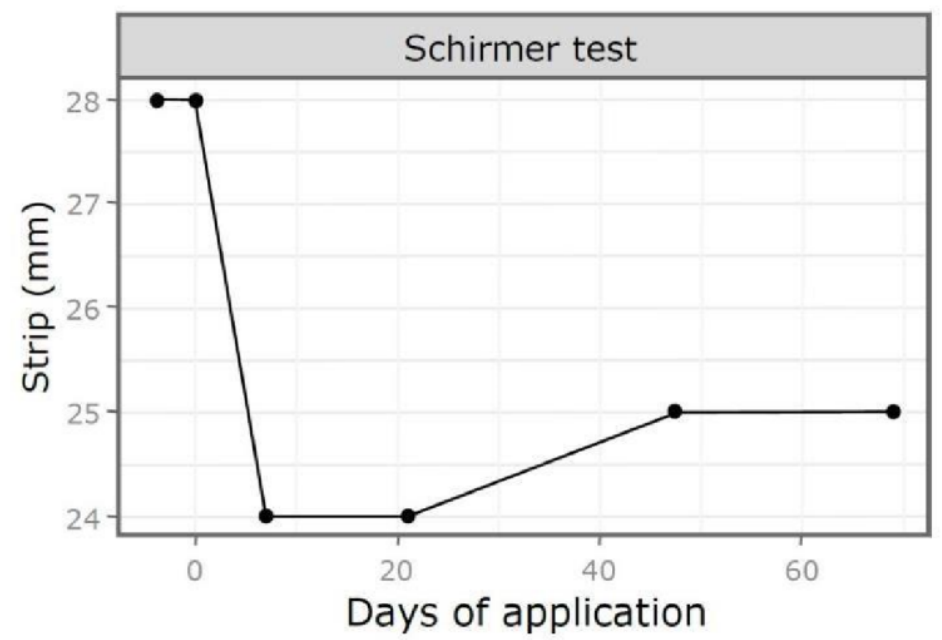

Figure 4. ST test showed decreased tear production after cATMSCs therapy. ST test was performed 4 days before the first application, on the day of application, 7, 21, 48, and 69 days. ST: Schirmer test.

\section{Discussion}

$\mathrm{CU}$ is an ophthalmopathy and can occur for various causes and to varying degrees of injury. When deep, it can permanently cause visual impairment (Gonçalves, 2000; Laus, Oriá, 1999).

The basis of conventional therapeutic alternatives in the medical and surgical clinic is the preservation of the eyeball to prevent ulcer progression and decrease/prevent infections to allow the limbal stem cells to have the time needed for wound healing (Huang, Tseng, 1991; Turner, 2010; Galera et al, 2009).

Usually, due to the regenerative capacity of the corneal epithelial layer, after injury, cells enter mitosis and started re-epithelialize the tissue between 4 to 7 days (Gelatt, 2003; 
Slatter, 2005). However, as ulcerations reach deeper layers, although the epithelium can cover the superficial portion, stromal filling does not occur as quickly and effectively, thus requiring more synthesis and deposition of collagen and proteoglycans, remodeling and avascular wound healing. Thus, in these cases, in general, natural repair requires much longer and may not occur uniformly, making the animal more susceptible to relapsing ulcerations (Morgan, Abrams, 1994; Stanley et al, 1998).

Cell therapy is effective because MSCs have shown to possess the capacity to transdifferentiate into ephithelial cells and ability to alter tissue microenvironment via secretion of soluble factors to tissue repair (Table1, Figure 1 and 2; Phinney, Prockop, 2007; Mansoor, et al., 2019).

MSCs presents properties of immunomodulation, anti-angiogenesis and antiinflammation by inhibiting: lymphocyte activation and proliferation; secretion of proinflammatory cytokines; pro-angiogenic factors and; infiltration of inflammatory cells and macrophage that offer the advantages in corneal reconstruction (Oh et al, 2008; Soleymaninejadian, et al., 2012; Ma, Chan, 2016; Mansoor, et al., 2019)

The case presented, despite being a patient with recurrent ulcer, after treated with allogeneic stem cells showed clinical improvement of all clinical signs present occurred in less than 14 days, which was effective since in this case the ulcer was refractory to the conventional treatment already submitted previously (Table 1 and Figure 2).

Thus, the results of this report are congruent and responsive, as the wound was treated and tissue repaired. Some authors show decrease in pain and therefore the stimulus of excessive tear production was ceased (Situ, Simpson, 2010). Some similar results can be correlated by the fluorescein test and also by the values of the ST, secretion and other symptoms associated with CU, which after therapy had baseline values (Figures 3 and 4). Therefore, this report agrees with the findings of other authors that corroborate demonstrating beneficial results of the use of stem cells in veterinary in general (Bakker et al, 2013) and especially in the treatment of ophthalmopathies in several species, both for CU in several species (Sel et al, 2012; Ma et al, 2006) as for other diseases such as keratoconjunctivitis sicca (Villatoro et al, 2015).

Conclusion 
In conclusion, cATMSC therapy contribute to the regeneration of corneal tissue in CU. Thus, the reproducibility and feasibility of this case report serve as the basis for research and application of new protocols with cell therapy in ophthalmic pathologies.

Bibliography

Bakker E, Ryssen BV, Schauwer C, Meyer E. Canine mesenchymal stem cells: state of the art, perspectives as therapy for dogs and as a model for man,Veterinary Quarterly $2013 ; 33(4): 225-233$.

Banks WJ. Histologia veterinária aplicada. 2a edição. São Paulo: Manole, 1992.

Baraniak PR, Mcdevitt TC. Stem cell paracrine actions and tissue regeneration. Regenerative Medicine 2010; 5(1):121-143.

Beam S, Correa MT, Davidson MG. A retrospective-cohort study on the development of cataracts in dogs with diabetes mellitus: 200 cases. Vet Ophthalmol 1999; 2:169-172.

Bobis S, Jarocha D, Majka M. Mesenchymal stem cells: characteristics and clinical applications. Folia Histochemica et Cytobiologica 2006; 44:215-230.

Deans RJ, Moseley, AB. Mesenchymal stem cells: Biology and potential clinical uses. Experimental Hematology 2000; 28:875-884.

Galera PD, Laus JL, Oriá AP. Afecções da túnica fibrosa. In: Laus, J. L. Oftalmologia Clínica e Cirúrgica em Cães e em Gatos. São Paulo; 2009, Roca, p. 69-96.

Gelatt KN. Veterinary Ophthalmology. Philadelphia. Editora Lea \& Febiger, 1991.

Gelatt KN. Manual de oftalmologia veterinária. Barueri: Editora Manole, 2003.

Gilger BC, Bentley E, Ollivier FJ. Diseases and surgery of the canine cornea and sclera. In: Gelatt KN. Veterinary ophthalmology. 4th ed. Iowa: Blackwell Publishing; 2007, p. 690- 752 .

Gonçalves GF. Ceratoplastia lamelar homóloga em cão com conservação em solução super saturada de açúcar ou glicerina. 2000. 54f. Dissertação (Mestrado em Medicina Veterinária) - Universidade Federal de Santa Maria, Santa Maria).

Huang AJ, Tseng SC. Corneal epithelial wound healing in the absence of limbal epithelium. Investigative Ophthalmology \& Visual Science 1991; 32:1, 96-105.

Koehler KG, Maggs DJ, Hollingsworth SR, Scagliotti RH, Nelson RW. Corneal sensitivity in dogs with diabetes mellitus. AJVR 2003, 64:1. 
Kern TJ. Corneopatias e escleropatias. Em: BIRCHARD, S.J. e SHERDING, R. G. Manual saunders - Clínica de pequenos animais. $2^{\circ}$ edição, São Paulo - SP, Editora Roca, 2003.

Lan Y, Kodati S, Lee HS, Omoto M, Jin Y, Chauhan SK. Kinetics and Function of Mesenchymal Stem Cells in Corneal Injury. Invest. Ophthalmol. Vis. Sci 2012, 53(7):3638-3644.

Laus JL, Oriá A. P. Doenças Corneanas em Pequenos Animais. Revista de Educação continuada do CRMV-SP 1999, 2(1):26-33.

Le Q, Xu J, Deng SX. Review. The diagnosis of limbal stem cell deficiency 2018, 16(1):58-69.

Ma Y, Xu Y, Xiao Z, Yang W, Zhang C, Song E, Du Y, Li L. Reconstruction of Chemically Burned Rat Corneal Surface by Bone Marrow-Derived Human Mesenchymal Stem Cells. Stem Cells 2006, 24:315-321.

Ma OK-F, Chan KH. Immunomodulation by mesenchymal stem cells: Interplay between mesenchymal stem cells and regulatory lymphocytes. World J Stem Cells 2016, 8(9):268278.

Mansoor H, Ong SH, Riau AK, Stanzel T, Mehta TS, Yam GHF. Current Trends and Future Perspective of Mesenchymal Stem Cells and Exosomes in Corneal Diseases. International Journal of Molecular Sciences 2019, 20(12):2853.

Morgan RV, Abrams KL. A comparison of six different therapies for persistent corneal erosions in dogs and cats. Vet Comp Ophthalmol 1994, 4:38-43.

Oh JY, Kim MK, Shin MS, Lee HJ, Ko JH, Wee WR, Lee JH. The Anti-Inflammatory and Anti-Angiogenic Role of Mesenchymal Stem Cells in Corneal Wound Healing Following Chemical Injury. Stem Cells 2008, 26:10471055.

Öner A. Stem Cell Treatment in Retinal Diseases: Recent Developments.

Turkish journal of ophthalmology 2018, 48(1):33-38.

Pittenger MF, Mackay AM, Beck SC, Jaiswal RK, Douglas R, Mosca J D, Moorman MA, Simonetti D W, Carig S, Marshak D R. Multilineage potential of adult human mesenchymal stem cells. Science 1999, 284(5411):143-7.

Phinney DG, Prockop DJ. Concise review: mesenchymal stem/multipotent stromal cells: the state of transdifferentiation and modes of tissue repair--current views. Stem Cells 2007, 25(11):2896-902.

Sel S, Schilling UM, Nass N, Simm A, Garreis F, Knak M, Storsberg J, Kaiser M, Kalinski T, Ehrich D, Bredehorn-Mayr T, Paulsen F. Bone marrow cells and CD117positive haematopoietic stem cells promote corneal wound healing. Acta Ophthalmol 2012, 90(5):e367-73. 
Situ P, Simpson TL. Interaction of corneal nociceptive stimulation and lacrimal secretion. Invest. Ophthalmol. Vis. Sci. 2010, 51(11):p. 5640-5645.

Sivak JM, Fini ME. MMPs in the eye: emerging roles for matrix metalloproteinases in ocular physiology. Prog Retin Eye Res. 2002, 21:1-14.

Slatter, D. Fundamentals of veterinary ophthalmology. 2.ed. Philadelphia, W. B. Saunders, 1990, p.257-303: Cornea and sclera.

Slatter D. Fundamentos de oftalmologia veterinária. $3^{\text {a }}$ ed. São Paulo: Roca; 2005.

Slatter, D. Manual de cirurgia de pequenos animais. $3^{\circ}$ ed. Vol 2, Barueri - SP, editora Manole, 2007.

Stanley RG, Hardman C, Johnson BW. Results of grid keratotomy, superficial keratectomy and debridement for the management of persistent corneal erosions in 92 dogs. Vet Ophthalmol 1998, 1:233-238.

Soleymaninejadian E, Pramanik K, Samadian E. Immunomodulatory properties of mesenchymal stem cells: cytokines and factors. American Journal of reproductive immunology 2012, 67(1):1-8.

Sridhar MS. Anatomy of cornea and ocular surface. Indian Journal of Ophthalmology 2018, 66(2):190-194.

Turner SM. Oftalmologia em Pequenos Animais. Rio de Janeiro: Elsevier, 2010.

Villatoro AJ, Fernandez V, ClarosS. Use of adipose-derived mesenchymal stem cells in keratoconjunctivitis sicca in a canine model. Biomed Res Int 2015, 527926.

Yao L, Bai H. Review: Mesenchymal stem cells and corneal reconstruction. Molecular Vision 2013, 19:2237-2243. 